\title{
ANALISIS PENGENDALIAN PERSEDIAAN BAHAN BAKU GUNA KELANCARAN PROSES PRODUKSI \\ (Studi Kasus : Pabrik Tahu ATB Gunung Sarik Kota Padang)
}

\author{
Usmiar, Leli Suwita, Wahyu Irawan \\ Universitas Muhammadiyah Sumatera Barat \\ usmiar@umsb.ac.id
}

\begin{abstract}
Abstrak : Penelitian ini bertujuan untuk mengetahui pengendalian persediaan bahan baku pabrik tahu ATB dengan menggunakan metode ROQ, SS, ROP, TIC untuk melakukan pengendalian persediaan bahan baku satu periode maka perlu melakukan perhitungan dalam produksi, teknis yang digunakan dalam perhitungan menggunakan EOQ (Penggunaan, biaya pemesanan, biaya, biaya penyimpanan) SS ( Pemakaian maxsimum, pemakaian rata-rata, lead time) ROP ( Persediaan pengaman, lead time, pemakaian rata-rata ) TIC ( total biaya penyimpanan dan total biaya pemesanan).

Hasil analisis pengendalian persediaan bahan baku pabrik tahu ATB gunung sarik, kuranji kota padang dapat disimpulkan sebagai berikut: Berdasarkan perhitungan metode EOQ pembelian bahan baku yang ekonomis sebesar $2.377 .722 \mathrm{~kg}$ dengan frekunsi pembelian bahan baku salama satu periode 98 kali dan apabila dihitung frekuensi pemesanan perhari maka 3.6 hari/ 3 hari sekali. Persediaan pengaman bahan baku kedelai pada perhitungan SS sebanyak $325 \mathrm{~kg}$. yang harus tetap ada dalam pabrik tahu ATB dan harus melakukan pembelian bahan baku kembali apabila kembali ke jumlah persediaan baku pengaman. Pada perhutungan ROP pabrik tahu ATB harus melakukan pemesanan kembali sebanyak 3.575. kg Pemesanan harus dilakukan sebelum persediaan bahan baku kedelai digudang habis, karena butuh Lead Time (waktu tunggu) sekitar 5 hari pada saat pemesanan hingga bahan baku kedelai tiba di gudang pabrik tahu.Berdasarkan perhitungan TIC diketahui total biaya persediaan bahan baku pada tahun 2019 yang ditanggung pabrik tahu ATB yaitu sebesar Rp 244.112,547,919.
\end{abstract}

\section{Kata Kunci : EOQ, SS, ROP, TIC}

Abstract : This study aims to determine the inventory control of ATB tofu factory raw materials using the ROQ, SS, ROP, TIC methods to control raw material inventory for one period, it is necessary to perform calculations in production, the technical used in calculations using EOQ (Use, cost ordering, cost, storage cost) SS (maximum usage, average usage, lead time) ROP (safety inventory, lead time, average usage) TIC (total storage cost and total ordering cost).

The results of the analysis of raw material inventory control for the tofu factory at ATB Gunung Sarik, Kuranji Kota Padang can be concluded as follows: Based on the calculation of the EOQ method, the purchase of economical raw materials is 2,377,722 $\mathrm{kg}$ with the frequency of purchasing raw materials for one period of 98 times and if the frequency of ordering is calculated per day then 3.6 days / every 3 days. The safety stock of soybean raw materials in the SS calculation is $325 \mathrm{~kg}$. which must remain in the ATB tofu factory and must re-purchase raw materials when it returns to the amount of safety standard inventory. In 
calculating the ROP, the ATB tofu factory had to reorder 3,575. $\mathrm{kg}$ Orders must be made before the supply of soybean raw materials in the warehouse runs out, because it takes a Lead Time (waiting time) of about 5 days at the time of ordering until the soybean raw materials arrive at the tofu factory warehouse. ATB tofu factory is Rp. 244.112,547,919.

Keywords : EOQ, SS, ROP, TIC

\section{A. PENDAHULUAN}

\subsection{Latar Belakang}

Pengendalian persediaan menjadi masalah dalam suatu proses produksi karena, jumlah persediaan akan menentukan dan mempengaruhi kelancaran produksi. Jumlah persediaan harus disesuaikan dengan tingkat produksi agar produksi berjalan lancar tanpa kendala pada persediaan bahan baku.

Semua perusahaan yang memproduksi dan barang mentah menjadi barang jadi pada dasarnya melakukan pengendalian terhadap persediaan bahan baku. Dalam pengendalian bahan baku dalam pengendalian bahan bakuyang menjadi masalah utama adalah persediaan bahan baku dalam pengendalian tersebut dapat ditentukan berapa kuantitas bahan baku yang akan dibeli dalam satu kali periode produksi, dan dapat diperkirakan juga biaya pemesanan pada setiap kali pemesanan bahan baku, juga dapat memperkirakan minimum kuantitas yang harus selalu ada dalam persediaan bahan baku. Agar perusahaan terhindar dari kemacetan produksi akibat kurangnya bahan baku, dapat mengendalikan berapa jumlah, maxsimum bahan baku dalam persediaan agar meminimalkan biaya persediaan.

Dengan adanya kebijakan pengendalian persediaan bahan baku yang diterapkan dalam perusahaan biaya persediaan dapat diminimumkan.

Untuk meminimumkan biaya tersebut dapat digunakan analisis Economic Order Quantity (EOQ).

Metode EOQ adalah metode yang digunakan untuk mengetahui volunr atau pemesanan yang paling ekonomis untuk dilakukan pada setiap kali pembelian bahan baku. Metode Economic Order Quantity (EOQ) yang diterapkan dalam perusahaan akan mampu meminimalisir terjadinya Out Of Stock sehungga tidak mengganggu proses produksi perusahaan dan mampu menghemat persediaan yang dikluarkan perusahaan karena adanya efesiensi persediaan dalam perusahaan. Selain itu dengan adanya penerapan metode EOQ perusahaan mampu mengurangi biaya penyimpanan, penghematan ruangan dan meminimalisirkan kemungkinan terjadinya masalah akibat penumpukan bahan.

Selain menentukan waktu pemesanan kembali bahan baku yang akan digunakan untuk kelancaran produksi. Untuk menentukan pemesann kembali dapat digunakan metode Re Order Point (ROP) yang dimaksud metode ROP adalah titik dimana persediaan waktu mengetahui biaya persediaan kembali. Untuk mengetahui biaya persediaan yang dikeluarkan pada setiap persediaan bahan baku dapat diketahui dengan metode Total Inventory Cost (TIC). Yang dimaksud dengan metoode TIC keseluruhan dari biaya persediaan yang dikeluarkan oleh perusahaan.dengan adanya metode EOQ, 
ROP, TIC maka perusahaan dapat mengendalikan produksi dengan bijak yang tentunya dengan efesiensi dan efektif. Semakin lancar proses produksi suatu perusahaan.

Penelitian ini dilakukan pada pabrik Tahu ATB di Gunung Sarik Kuranji, Kota padang yang akitifitas perusahaan perusahaan mengelola kedelai menjadi tahu. Kedelai adalah sebagai bahan bku dan tahu merupakan hsil produksi.

Produksi pabrik ATB di Gunung Sarik Kuranji, Kota Padang dalam menjelaskan aktifitas produksinya mengalami permsalahan yang berhubungan dengan bahan baku. Titik pemesanan dari perusahaan tersebut kurang memperhatikan pengendalian terhadap persediaan bahan baku sehigga proses produksi perusahaan terganggu.

Untuk itu berdasarkan uraian diatas peneliti tertarik untuk melakukan penelitian dipabrik tahu ATB yang berlokasi di Gunung Sarik Kuranji, Kota Padang dengan judul "ANALISIS PENGENDALIAN PERSEDIAAN BAHAN BAKU GUNA KELANCARAN PRODUKSI TAHU ATB”.

\subsection{Rumusan Masalah}

Bagaimana pengendalian persediaa bahan baku guna kelancaran produksi dengan menggunakan metode perhitungan EOQ pad Pabrik Tahu ATB di Sungai Sarik Kuranji, Kota Padang.

\subsection{Tujuan Penelitian}

Untuk mengetahui pengendalian persediaa bahan baku guna kelancaran produksi dengan menggunakan metode perhitungan EOQ pad Pabrik Tahu ATB di Gunung Sarik Kuranji, Kota Padang

\section{B. TINJAUAN PUSTAKA}

\subsection{Pengertian Persediaan}

Assauri (2008:237)mengemukakan bahwa "persediaan adalah sebagai suatu aktiva yang meliputi barang-barang milik perusahaan dengan maksud untuk dijual dalam suatu periode usaha yang normal, atau persediaan barang-barang yang masih dalam pengerjaan /proses produksi, ataupun persediaan barang baku yang menunggu penggunaanya dalam suatu proses produksi.

\subsection{Jenis-jenis Persediaan}

MenurutHandoko, (2019:334)jenis persediaan dapat dibedakan atas.

1. Persediaan bahan mentah (raw material),yaitu persediaan barang-barang berujud seperti baja, kayu dan komponen-komponen lainnya yang digunakan dalam proses produksi.

2. Persediaan komponen-komponen rakitan (purchased parts/ components), yaitu persediaan barang-barang yang terdiri dari komponen-komponen yang diperoleh dari perusahaan lain, dimana secara langsung dapat dirakit menjadi suatu produk.

3. Persediaan bahan pembantu atau penolong (supplies), yaitu persediaan barang-barang yang diperlukan dalam proses produksi, tetapi tidak merupakan bagian atau komponen barang jadi. 
4. Persediaan barang dalam proses (work in process), yaitu persediaan barang- barang yang merupakan keluaran dari tiap-tiap bagian dalam proses produksi atau yang telah diolah menjadi suatu bentuk, tetapi masih perlu diproses lebih lanjut menjadi barang jadi.

5. Persediaan barang jadi (finished goods), yaitu persediaan barang barang yang telah selesai diproses atau diolah dalam pabrik dan siap untuk dijual atau dikirim kepada langganan.

\subsection{Fungsi-fungsi Persediaan}

Menurut (Handoko, 2019:337) persediaan bahan bakudisebutkan bahwa fungsi persediaan terbagi menjadi tiga macam yaitu:

1. Fungsi decoupling

Fungsi penting persediaan adalah memungkinkan operasi-operasi perusahaan internal dan eksternal mempunyai kebebasan (independensi).Persediaan decoupling ini memungkinkan perusahaan dapat memenuhi permintaan langganan tanpa menunggu suplier.

2. Fungsi economics lot sizing Melalui penyimpanan persediaan, perusahaan dapat memproduksi dan membeli sumber-sumber daya dalam kualitas yang dapat mengurangi biaya-biaya per unit.Dengan persediaan lot size ini akanmempertimbangkan penghematan pengeluaraan persediaan.

3. Fungsi antisipasi

Suatu perusahaan sering menghadapi fluktuasi permintaan yang dapat diperkirakan dan diramalkan berdasarkan pengalaman atau data di masa lalu. Disamping itu perusahaan juga sering dihadapkan pada ketidakpastian jangka waktu pengiriman barang kembali sehingga harus dilakukan antisipasi untuk cara menanggulanginya.

\subsection{Pengertian Persediaan Bahan Baku}

Setiap perusahaan yang menyelenggarakan kegiatan produksi pasti memerlukan persediaan bahan baku yang diharapkan perusahaan tersebut dapat melakukan proses produksi sesuai kebutuhan atau permintaan konsumen.

Menurut Riyana, (2018) mendefinisikan, Persediaan bahan baku merupakan aktiva perusahaan yang digunakan untuk proses produksi didalam suatu perusahaan dan disediakan untuk memenuhi kebutuhan dan keinginan pelanggan setiap waktu.

\section{METODE PENELITIAN}

\subsection{Teknik Analisis dengan EOQ}

Dalam penelitian ini teknik analisis data yang digunakan untuk mengetahui pengendalian persediaan bahan baku pada pabrik tahu ATB dengan menggunakan metode EOQ.

Perhitungan pembelian yang paling ekonomis $E O Q$

\section{Economic Order Quantity (EOQ)}


Menurut Handoko, (2019:240) Dalam teori ekonomi perhitungan pemesanan bahan baku secara efektif atau Economic Order Quantity dapat dilakukan dengan menggunakan rumus perhitungan EOQ.

Rumus:

$$
\boldsymbol{E O Q}=\sqrt{\frac{2 S D}{H}}
$$

\section{Dimana:}

$\mathrm{D}=$ Penggunaan atau permintaan yang diperkirakan per periode waktu.

$\mathrm{S}=$ Biaya pemesanan (persiapan pesanan dan penyaiapan mesin) per pesanan.

$\mathrm{H}$ = Biaya penyimpanan per unit per periode.

Dalam perhitungan EOQ untuk mengetahui quantity (jumlah penggunaan barang) dalam satu periode.Untuk mengetahui $\mathrm{Q}$, maka dilakukan perhitungan dengan sesuai rumus diatas.

Rumus : F.P

Keterangan :

FP : Frekuensi Pemesanan

D : Penggunaan

EOQ : Economic Order Quantity

\section{Safety Stock (SS)}

Perhitungan ini untuk mengetahui persediaan pengaman bahan baku atau safety stock

Rumus:

Keterangan :

$$
\text { SS }=\text { PM }- \text { PRR x LT }
$$

$\mathrm{SS}=$ Persediaan Pengaman

PM $=$ Pemakaian Maxsimum

PRR $=$ Pemakian Rata-rata

LT = waktu tunggu dari pemesanan hingga tiba digudang

\section{Reorder point (ROP)}

analisis ini untuk mengetahui titik pemesanan kembali yang harus dilakukan agar pembelian bahan baku yang sudah ditetapkan dalam EOQ.

Rumus :

$$
\text { ROP }=\mathrm{SS}+(\mathrm{LT} \times \mathrm{PBB})
$$

Keterangan:

ROP = titik yang menjukkan jumlah persediaan bahan baku sehingga perusahaan harus memesan kembali $(\mathrm{kg})$

$\mathrm{SS}=$ Safety Stock (persediaan pengaman) $(\mathrm{kg})$

LT = waktu tunggu antara pemesanan bahan baku sampai kedatangan di gudang (hari)

$\mathrm{PBB}=$ Pemakaian rata-rata dalam satu hari $(\mathrm{kg})$

\section{TIC ( total biaya persediaan bahan baku )}


Rumus

$$
T I C=\left(\frac{D}{Q} x S\right)+\left(\frac{Q}{2} x H\right)
$$

Keterangan :

$\mathrm{TIC}=$ total inventory cost $(\mathrm{Rp})$

$\mathrm{D}=$ Pemakaian bahan baku dalam satu periode

$\mathrm{Q}=$ Pembelian Ekonomis

$\mathrm{S}=$ Biaya Pemesanan

$\mathrm{H}=$ Biaya Penyimpanan (unit/tahun

\section{PEMBAHASAN}

\section{1. . Perhitungan dalam Pengendaliaan Persediaan bahan baku}

Berdasarkan data yang diperoleh dari pabrik tahu ATB yang merupakan usaha industri tahu .perhitungan dan analisis pengendalian persediaan bahan baku pada pabrik tahu ATB digunakan analisis $(E O Q, S S, R O P, T I C)$ berikut adalah perhitungan dan analisis pengendalian persediaan bahan baku pad pabrik tahu ATB.

\subsubsection{Perhitungan EOQ (Economic Order Quntity)}

Dalam perhitungan EOQ yaitu menentukan besarnya kuantitas setiap kali pembelian yang paling ekonomis, untuk mengetahuinya maka perlu perhatikan langkahlangkah perhitungan EOQ yaitu pembelian selama satu periode, biaya pemesenan dan biaya penyimpanan.

Berdasarkan hasil penelitian pada pabrik tahu ATB, total pembelian bahn baku kedelai pada tahun 2019. Adalah 36.000 sebanyak selama satu bulan 8 kali pemesanan pada sehingga selama satu tahun 96 kali pemesanan. Pada bahan baku yang digunakan selama satu tahun 2019 yaitu sebanyak $234.000 \mathrm{~kg}$ biaya pemesanan pada tahun 2019 yang dikeluarkan 48.000.000

Untuk menghitung jumlah pemesanan ekonomis dengan menggunkan metode EOQ sebagi berikut:

$$
\begin{aligned}
& \text { Keterangan : } \\
& \mathrm{S}=24.780 .000 \\
& \mathrm{D}=234.000 \mathrm{~kg} \\
& \mathrm{H}=48.000 .000 / 234.000=205.128 \\
& \mathrm{EOQ}=\sqrt{\frac{2 .(24.780 .000) \cdot(234.000)}{(205.128)}}= \\
& \mathrm{EOQ}=\sqrt{\frac{(11.597 .040) \cdot(234.000)}{(205.128)}} \\
& \mathrm{EOQ}=\sqrt{5.653 .562 .65} \\
& \mathrm{EOQ}=2.377 .722 \mathrm{Kg}
\end{aligned}
$$$$
\mathrm{EOQ}=\sqrt{\frac{2 \cdot D \cdot S}{H}}
$$

Berdasarkan perhitungan metode EOQ (Economic Order Quantity) diperoleh bahwa jumlah pembelian bahan baku kedelai paling ekonomis dalam sekali Pemesanan sebanyak 2.377,722. Kg. 
Untuk mengetahui frekuensi pembelian bahan baku bahan baku kedelai, maka dapat di hitung dari.

F.P $=\frac{234.000}{2.377,722 \mathrm{Kg}}=98$ kali dalam satu periode

Jika di hitung dalam perhari 360 hari : 98 kali $=3.6$ Hari artinya pembelian bahan baku dapat dilakukan 3 hari sekali.

\subsubsection{Perhitungan SS(Safety Stock)}

Pada persediaan pengaman (Safety Stock) diperuntukkan menghadapi apabila terjadinya kenaikan pemakaian bahan baku diluar kebutuhan yang diperhitungkan.

Apabila terjadinya keterlambatan kedatangan barang yang dipesan. Sehingga dengan adanya persediaan pengaman dapat mengatasi adanya fluktuasi permintan dan waktu tunggu kedatangan bahan baku. Apabila terjadinya kekurangan bahan baku kedelai maka akan mengakibatkan proses produksi di pabrik tahu ATB jadi terhambat.

Untuk mengatasi kekurangan bahan baku itu terjadi maka dilakukan pengaman persediaan bahan baku (Safety Stock). Untuk menentukan Safety Stock maka perlu melakukan persediaan pengaman untuk mengurangi biaya akibat kehabisan persediaan. Apabila persediaan besar maka semakin kecil biaya akibat kehabisan persediaan bahan baku. Pabrik tidak akan mengalami kerugian akibat tidak perpenuhinya permintaan konsumen karena kehabisan persediaa, dan proses produksi berjalan lancar namun adanya persediaan pengaman yang apabila semakin tinggi persediaan pengaman mak akan semakin besar pula biaya penyimpanan bahan baku. Untuk itu dalam hal ini pemilik pabrik tahu ATB harus cermat dan tepat dalam menentukan persediaan pengaman agar persediaan tersebut dapat berperan sesuai dengan fungsinya.

Perhi tungan Safety Stock

Safety Stock $=($ Pemakaian maksimum - pemakaian rata-rata $) \times$ Lead Time

Safety Stock $=234.0000 \frac{234}{360} \times 5$ hari

Safety Stock $=325 \mathrm{~kg}$ pertahun.

Berdasarkan perhitungan dengan metode Safety Stock menunukkan bahwa persediaan pengaman bahan baku kedelai $325 \mathrm{~kg}$.harus tetap selalu ada pada pabrik tahu ATB untuk mengantisipasi terjadinya kekurangan bahan baku dan apabila sudah menunjukkan $325 \mathrm{~kg}$ maka pabrik tahu ATB sudah harus melakukan pembelian bahan baku kembali.

\subsubsection{Perhitungan ROP (Reorder Point)}

Metode Reoder Point ROP atau pemesanan kembali untuk mengetahui kapn pabrik tahu melakukan pemesanan kembali sehingga penerimaan bhan yag dipesan dapat tepat waktu. Dalam pembelian bahan baku tidak dapat langsung diterima pada hari melakukan pembelian.

Perhitungan untuk menghitung ROP :

$$
\mathrm{ROP}=\mathrm{SS}+(\mathrm{LT} \times \mathrm{PBB}
$$




$$
\begin{aligned}
\mathrm{SS} & =325 \mathrm{~kg} . \\
\mathrm{LT} & =5 \text { Hari. } \\
\mathrm{PBB} & =650 \mathrm{~kg} .(10 \% \text { diatas pemakaiaan rata-rata perhari }) \\
\mathrm{ROP} & =325+(5 \times 650) \\
& =325+3.250 \\
& =3.575 \mathrm{~kg} .
\end{aligned}
$$

Berdasakan perhitungan reorder point (ROP) yaitu sebanyak $3.575 \mathrm{~kg}$, maka pabrik tahu ATB sudah harus melakukan pemesanan kembali. Pemesanan harus dilakukan sebelum persediaan bahan baku kedelai digudang habis, karena butuh Lead Time (waktu tunggu) sekitar 5 hari pada saat pemesanan hingga bahan baku kedelai tiba di gudang pabrik tahu.

\subsubsection{Perhitungan TIC (Total Inventory Cost)}

Dalam perhitungan TIC adalah menentukan jumalah biaya-biaya yang dikeluarkan dalam persediaan bahan baku, untuk mengentahui maka perlu melakukan perhitungan sebagai berikut:

Dalam perhitungan TIC yang dihitung adalah biaya pemesanan dan biaya penyimpanan.

$$
\begin{aligned}
\mathrm{TIC} & =\left[\frac{D}{Q}\right] \mathrm{S}+\left[\frac{Q}{2}\right] H \\
\mathrm{TIC} & =\left[\frac{234.000}{2.377 .722}\right] 24.780 .000\left[\frac{2.377 .722}{2}\right] 205.128 \\
\mathrm{TIC} & =243.868,711+243.868,679,208 \\
\mathrm{TIC} & =244.112,547,919
\end{aligned}
$$

Pada perhitungan diatas maka diketahui total biaya persediaan bahan baku yang ekonomis pada tahun 2019 ditanggung pabrik tahu ATB yang terdiri

\section{E. PENUTUP} dari biaya pemesanan biaya penyimpanan, yaitu sebesar Rp 244.112,547,919.

\subsection{Kesimpulan}

berdasarkan hasil pembahasan analisis pengendalian persediaan bahan baku pabrik tahu ATB Gunung Sarik, Kuranji Kota Padang dapat disimpulkan sebagai berikut:

Berdasarkan perhitungan metode EOQ pembelian bahan baku yang ekonomis sebesar 2.377.722 $\mathrm{Kg}$ dengan frekunsi pembelian bahan baku salama satu periode 98 kali dan apabila dihitung frekuensi pemesanan perhari maka 3.6 hari/ 3 hari sekali. Persediaan pengaman bahan baku kedelai pada perhitungan SS sebanyak $325 \mathrm{Kg}$. yang harus tetap ada dalam pabrik tahu ATB dan harus melakukan pembelian bahan baku kembali. Apabila kembali ke jumlah persediaan baku pengaman.Pada perhutungan ROP pabrik tahu ATB harus melakukan pemesanan kembali sebanyak 3.575. Kg Pemesanan harus dilakukan sebelum persediaan bahan baku kedelai digudang habis, karena butuh Lead Time (waktu tunggu) sekitar 5 hari pada saat pemesanan hingga bahan baku kedelai tiba di gudang pabrik tahu.Berdasarkan perhitungan TIC diketahui total biaya persediaan 
bahan baku pada tahun 2019 yang ditanggung pabrik tahu ATB yaitu sebesar Rp $244.112,547,919$.

\subsection{Saran}

Berdasarkan kesimpulan diatas, mka peneliti dapat memberikan saran kepada Paabrik Tahu ATB usaha ibu Srileni Yati.

Pabrik tahu ATB sebaiknya meninjau kembali kebijakan persediaan bahan baku kedelai yang selama ini telah digunakan oleh pabrik Tahu ATB.dan dapat mencoba mengaplikasikan metode Economic Erder Quantity untuk menentukan kuantitas pemesanan yang ekonomis.Pabri Tahu ATB sebaiknya menentukan besarnya persediaan pengaman, pemesanan kembali untuk menghindari resiko kehabisan bahan baku dan keelebihan bahan baku sehingga dapat meminimalkan biaya bahan baku kedelai.

\section{F. DAFTAR PUSTAKA}

Abdul Hakim, 2007. Manajemen Keuangan Bisnis. Bogor Ghalia Indonesia

Dwi Yuniarti, 2013. Analisis Persediaan Bahan Baku Kedelai Diindustri Pengolahan Tempe Sammodra. Surakarta Fakultas Pertanian Universitas Sebelas Maret

Eddy Herjanto, Manajemen operasi edisi.Revisi Jakarta Gramedia.2010

Maya Okta Riyana, 2018. Analisis Persediaan Bahan Baku Dengan Menggunakan Metode Ecomonic Order Quantitative (EOQ) Terhadap Kelancaran Produksi Pada Industri Pembuatan Kain Perca Menurut Spektif Ekonomi Islam. Lampung fakultas ekonomi dan bisnis islam Universitas Islam Negeri Raden Intan Lampung

Mohammad Iqbal 2010 Analisis Trend Dengan Metode Kuadrat Terkecil Untuk Meramalkan Perkembangan.Malang Fakultas Sains Dan Teknologi Universitas Negeri Maulana Malik Ibrahim.

Rangkuti Freddy. 2000. Manajemen Persediaan Aplikasi di Bidang BisnisBahan kuliah bagi ingin mendalami manajemen operasional dan produksi Jakarta, PT Raja Grafindo Parsada.

SofjanAssauri, edisi revisi 2008. Manajemen Produksi Dan Operasi. Jakarta, lembaga penerbit fakultas ekonomi universitas Indonesia

T. Hani Hnadoko, edisi 1 2019.dasar-dasar manajemen produksi dan operasi. Yogyakarta, BPFE-Yogyakarta 